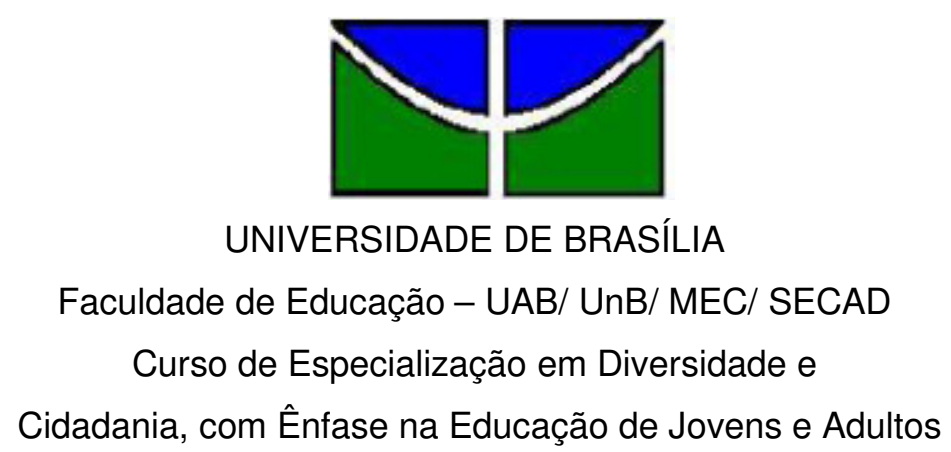

GLEYCON RODRIGO DA SILVA GOMES

\title{
PROJETO DE VIDA: UMA ALTERNATIVA PARA SE COMBATER A EVASÃO NA EDUCAÇÃO DE JOVENS E ADULTOS - EJA
}

BRASÍLIA, DF 


\author{
UNIVERSIDADE DE BRASÍLIA \\ Faculdade de Educação - UAB/ UnB/ MEC/ SECAD \\ Curso de Especialização em Diversidade e \\ Cidadania, com Ênfase na Educação de Jovens e Adultos
}

GLEYCON RODRIGO DA SILVA GOMES

\title{
PROJETO DE VIDA: UMA ALTERNATIVA PARA SE COMBATER A EVASÃO NA EDUCAÇÃO DE JOVENS E ADULTOS - EJA
}

CARMENÍSIA JACOBINA AIRES

ALEXANDRA PEREIRA DA SILVA

PROJETO DE INTERVENÇÃO

BRASÍLIA, DF Julho/2010 


\title{
UNIVERSIDADE DE BRASÍLIA
}

Faculdade de Educação - UAB/ UnB/ MEC/ SECAD

Curso de Especialização em Diversidade e

Cidadania, com Ênfase na Educação de Jovens e Adultos

\author{
GLEYCON RODRIGO DA SILVA GOMES
}

\section{PROJETO DE VIDA: UMA ALTERNATIVA PARA SE COMBATER A EVASÃO NA EDUCAÇÃO DE JOVENS E ADULTOS - EJA}

Trabalho de conclusão do Curso de Especialização em Educação na Diversidade e Cidadania, com Ênfase em EJA, como parte dos requisitos necessários para obtenção do grau de Especialista na Educação de Jovens e Adultos.

CARMENÍSIA JACOBINA AIRES

Professora Orientadora

ALEXANDRA PEREIRA DA SILVA

Tutora Orientadora

MARIA MADALENA TORRES

Avaliadora Externa

BRASÍLIA, DF Julho/2010 
Ai de nós, educadores, se deixamos de sonhar sonhos possíveis. (...) Os profetas são aqueles ou aquelas que se molham de tal forma nas águas da sua cultura e da sua história, do seu povo, que conhecem o seu aqui e o seu agora e, por isso, podem prever o amanhã que eles mais do que advinham, realizam. 


\section{RESUMO}

A aplicação do Projeto de Vida: uma alternativa para se combater a evasão na Educação de Jovens e Adultos na Escola Municipal Rui Barbosa visa reverter o quadro crítico das elevadas taxas de evasão escolar que se observa nesta modalidade de ensino no decorrer dos semestres letivos. O Projeto será realizado em três fases, sendo a primeira a de constatação, a segunda de visitação e a terceira de execução das oficinas de ensino que terão por objetivos promover a permanência de alunos na escola, auxiliando-os a adotarem uma postura persistente na busca dos propósitos com vista à realização de seus Projetos de Vida, conscientiza-os sobre a necessidade da educação formal, despertando o interesse pelos estudos, alem de incentivá-los a formularem projetos de vida através de propósitos que os ajudarão na conquista dos melhores resultados, por fim promove a formação de cidadãos críticos e conscientes de suas responsabilidades e de seus direitos.

Palavras-chave: propósito e projeto de vida, evasão escolar e Educação de Jovens e Adultos. 


\section{LISTA DE TABELAS}

4.1 Evasão Escolar - Realidade Educacional na EJA - Tabela 1 - Quatro principais

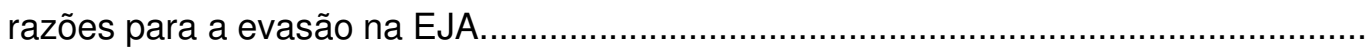

6 Atividades/Responsabilidades - Tabela 2 - Principais justificativas dadas pelos alunos que se evadiram da EJA na Escola Municipal Rui Barbosa................................ 


\section{LISTA DE GRÁFICOS}

4.3 Realidade Educacional na EJA - Conseqüência da Problemática - Gráfico 1 - Escola

Municipal Rui Barbosa - Evasão na (EJA) - 2ํㅗㄹ semestre 2009.

4.3 Realidade Educacional na EJA - Conseqüência da Problemática - Gráfico 2 - Escola

Municipal Rui Barbosa - Evasão na (EJA) - 2ํsemestre 2009

10 Acompanhamento e avaliação Escola Municipal Rui Barbosa - Gráfico 3 - Meta de Evasão

para $20101^{\circ}$ Segmento.

10 Acompanhamento e avaliação Escola Municipal Rui Barbosa - Gráfico 4 - Meta de Evasão

para $201022^{\circ}$ Segmento 


\section{LISTA DE SIGLAS}

AJA - Alfabetização de Jovens e Adultos

CONFINTEA - Conferencia Internacional de Educação de Adultos

EJA - Educação de Jovens e Adultos

IBGE - Instituto Brasileiro de Geografia e Estatística

PNAD - Pesquisa Nacional por Amostra de Domicílio 


\section{SUMÁRIO}

1 DADOS DE IDENTIFICAÇÃO ......................................................................... 10

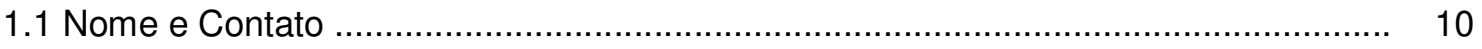

1.2 Turma

2 DADOS DE IDENTIFICAÇÃO DO PROJETO.......................................................... 10

2.1 Título:

2.2 Área de Abrangência: ................................................................................. 10

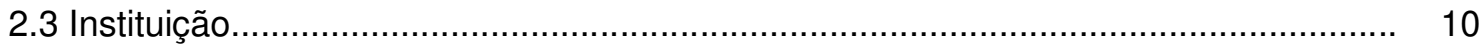

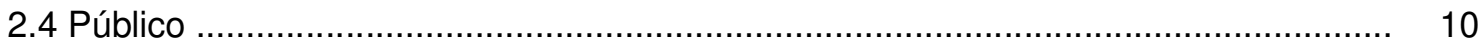

2.5 Período de Execução................................................................................ 10

3 AMBIENTE INSTITUCIONAL........................................................................ 11

4 JUSTIFICATIVA E CARACTERIZAÇÃO DO PROBLEMA......................................... 13

4.1 Evasão Escolar - Realidade Educacional na EJA …………............................... 13

4.2 Obstáculos a Serem Vencidos na EJA................................................................ 15

4.3 A necessidade de se elaborar um Projeto de Vida .............................................. 16

5 OBJETIVO GERAL............................................................................... 18

5.1. Objetivos Específicos.............................................................................. 18

6. ATIVIDADES/RESPONSABILIDADES ......................................................... 18

7. CRONOGRAMA

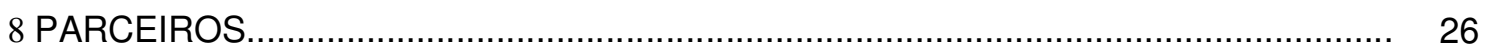

9 ORÇAMENTO.

10 ACOMPANHAMENTO E AVALIAÇÃO......................................................... 27

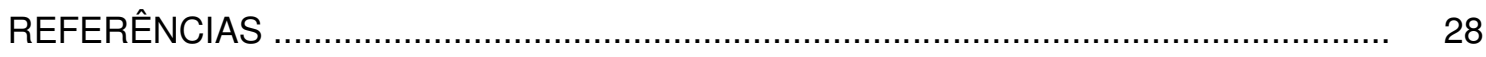

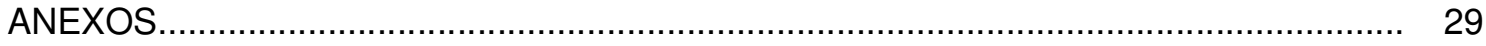

1 Aplicação do Projeto de Vida: uma alternativa para se combater a evasão escolar na Educação de Jovens e Adultos........................................................................... 29

2 Relatório de Participação no Projeto de Vida: uma alternativa para se combater a evasão escolar na Educação de Jovens e Adultos.................................................... 30

3 Avaliação do Projeto de Vida: uma alternativa para se combater a evasão escolar na Educação de Jovens e Adultos 


\section{DADOS DE IDENTIFICAÇÃO}

1.1Nome: Gleycon Rodrigo da Silva Gomes, (61)3627-33-36 ou 9844-94-94

gleycon.rodrigo@hotmail.com ou geogleys@gmail.com.

1.2 Turma: H, Pólo de Santa Maria

\section{DADOS DE IDENTIFICAÇÃO DO PROJETO}

2.1 Título: Projeto de Vida: uma alternativa para se combater a evasão escolar na Educação de Jovens e Adultos - EJA.

2.2 Área de Abrangência: Local.

2.3 Instituição:

A Escola Municipal Rui Barbosa é uma instituição pública que está subordinada à Secretaria de Educação de Valparaíso de Goiás e fica localizada na área urbana do Jardim Oriente, Rua 13, Área especial, em Valparaíso de Goiás - GO. O telefone para contato é (61) 3629-60-34 e o Codigo de Endereçamento Postal é o 72.870-000.

\subsection{Público:}

O público alvo deste Projeto são os alunos trabalhadores ou não, que estudam no primeiro e no segundo segmentos, na modalidade EJA, em sua grande maioria oriundos da comunidade do Jardim Oriente Setor de Chácaras Anhanguera A e B e algumas quadras da Morada Nobre, Céu Azul e Valparaíso II.

Alguns desses alunos são jovens que devido à faixa etária, não puderam ter suas vagas garantidas no ensino regular e outros são adultos e/ou idosos que por motivos sociais e/ou financeiros não tiveram a oportunidade de freqüentar uma escola.

2.5 Período de Execução:

Início: 02/08/2010 - Término: 10/12/2010. 


\section{AMBIENTE INSTITUCIONAL}

A Escola Municipal Rui Barbosa foi inaugurada em dezembro de 2000, iniciando suas atividades em janeiro de 2001, isto é, antes da regulamentação que a legitimou através da Lei $n^{\circ} 340$, de 23 de novembro de 2001, oferecendo o Ensino Fundamental ( $1^{\circ}$ ao $5^{\circ}$ ano), funcionando no turno matutino das $8 \mathrm{~h}$ às $12 \mathrm{~h}$. atendendo a 301 alunos e no período vespertino das $13 \mathrm{~h}$ às $17 \mathrm{~h}$ atendendo a 304 educandos.

A área física da escola é composta por uma secretaria e uma sala de professores, (ambas com banheiro), uma sala de recuperação, oito salas de aulas, uma biblioteca, uma cozinha, um depósito de alimentos, um banheiro masculino e um feminino (contendo seis vasos cada), um enorme pátio semi coberto. Na parte exterior possui um mini-parque de diversões, um campo de areia e uma área de estacionamento. A escola e completamente cercada por muros para maior segurança de sua clientela.

A partir de 2003, a escola passou a oferecer no período noturno a modalidade de Educação de Jovens e Adultos ( $1^{\circ}$ e $2^{\circ}$ segmentos), funcionando das $19 \mathrm{~h}$ às $23 \mathrm{~h}$. atendendo a 225 alunos sendo 59 no $1^{\circ}$ segmento e 166 no $2^{\circ}$ segmento e sua clientela é formada por famílias de classe baixa e média renda econômica.

A escola inaugurou, no dia 03 de maio de 2010, uma extensão, sendo um anexo situado na Quadra 25, Chácara 04, no Setor Anhangüera-B, que oferece Educação Infantil (maternal Jardim I, II) e atende a 156 crianças de 02 a 05 anos de idade, sendo 81 no matutino e 75 no vespertino.

A direção geral é o núcleo executivo que organiza, supervisiona e controla as atividades desenvolvidas no estabelecimento. A diretora Elenir Souza Nunes é uma profissional legalmente habilitada, responsável pela administração da escola, nomeada pela chefe do Poder Executivo do Município de Valparaíso de Goiás a prefeita Leda Borges de Moura (PSDB), cujo mandato será de 2009-2012.

A coordenação pedagógica é exercida por professores com experiência no campo da docência que além de assessorar a diretora estão atentos ao planejamento acompanhando e avaliando o desenvolvimento do processo pedagógico da escola. Revisando e buscando o melhores resultados nos projetos desenvolvidos. $\mathrm{Na}$ EJA, atua como coordenadora pedagógica, Terezinha Soares Leão e como coordenador de Turno, Oscar Ferreira Sa.

O Pessoal Docente é constituído por professores, integrantes do quadro de pessoal do Município, lotado na escola. Atuam como professore da EJA: Ana Maria Alves Noleto de Andrade; Ariosvaldo Pereira Valdivino, Eva Gomes dos Santos, Gleycon Rodrigo da Silva Gomes, José Maria Souza Nunes, Jussara Silva de Oliveira Miranda, Maria do Socorro 
Carlos Ramalho, Maria do Socorro e Silva Guimarães, Rildailda Cordeiro Ramos, Rosileide Barbosa Santos e Severino Pereira dos Reis.

A secretaria escolar é subordinada a Direção e é o Órgão Técnico Administrativo encarregado dos trabalhos de escrituração, correspondência e arquivo dos atos pertinentes a ação escolar. A secretaria está sob a responsabilidade de Maria Helena Alves Borba, pessoa legalmente habilitada e autorizada pelo órgão competente, coadjuvada por auxiliares administrativos (auxiliar de secretaria) com Leonilson Marques Soares e Francisca A Costa Arantes.

As merendeiras Maria Arcanja Dantas Mota e Maria de Araújo Nunes, cuidam para a boa prática no preparo e conservação dos alimentos para os alunos da EJA e as serventes Francisca Oneida Ferreira de Souza e a Maria Dionísia Barcelos dos Anjos, zelam da infraestrutura física da escola no período noturno.

No $1^{\circ}$ segmento ( $1^{\circ}$ ao $4^{\circ}$ período) da EJA a escola desenvolve os Projetos meio ambiente/lixo reciclável e Produção e interpretação de texto (professora Rildailda Cordeiro Ramos). No $2^{\circ}$ segmento (5ำ ao $8^{\circ}$ período), desenvolve os Projetos: Festa do amigo (professor Severino de Vasconcelos Andrade), Cidadania (professor Gleycon Rodrigo da Silva Gomes), Jogos matemáticos (professor Ariosvaldo Pereira Valdivino) e no $1^{\circ}$ e $2^{\circ}$ segmento o Projeto Região Centro-Oeste (coordenadora Terezinha Soares Leão).

A escola tem como objetivos principais e estratégicos assegurar a melhoria do processo de ensino e aprendizagem, buscando diminuir a repetência e o abandono do ensino, visando à integração da escola à comunidade, fortalecendo a rotina escolar. A sala de aula é um espaço de vivências múltiplas e, sobretudo, no seu interior e na dinâmica do cotidiano escolar, professores e alunos exercem seus papéis não apenas como agentes mais como atores. O educador é responsável pela função educativa de adaptação do indivíduo (aluno), de modo a integrá-lo à vida em sociedade e assim contribuir para a estabilidade social.

No que se refere à EJA observa-se que esses objetivos também são almejados, porém, as características dos estudantes desta modalidade divergem daqueles atendidos pelo ensino fundamental regular, o que de certa maneira compromete o alcance desses objetivos. Nesse sentido, medidas simples como aproximar o professor da realidade de seus alunos contribuiria para a compreensão da diferença entre o ensino regular e a modalidade EJA, diferença essa traduzida em números expressivos relacionados à evasão escolar.

Embora não exista uma solução única para diminuir a desistência por parte dos estudantes da EJA, é possível através de algumas experiências tentar minimizar a situação atual no que se refere à evasão escolar. Este é o desafio que é posto para os profissionais da Escola Municipal Rui Barbosa, que visa ser alcançado trabalhando-se a questão da 
motivação na aprendizagem, na construção de objetivos, no planejamento de um projeto de vida que visem à concretização dos propósitos idealizados pelos alunos.

\section{JUSTIFICATIVA E CARACTERIZAÇÃO DO PROBLEMA}

\subsection{Evasão Escolar - Realidade Educacional na EJA}

Segundo o Documento Base Nacional Preparatório à VI CONFINTEA, Conferencia Internacional de Educação de Adultos (2008, p. 4) no Brasil ainda existem 31 milhões de analfabetos funcionais que não completaram a $4^{\circ}$ série do Ensino Fundamental. O IBGE (Instituto Brasileiro de Geografia e Estatística-2006) registrou a cifra de 14,4 milhões de analfabetos com 15 anos ou mais no Brasil. Dados da PNAD - (Pesquisa Nacional por Amostra de Domicílio-2006) demonstra que a Alfabetização de Jovens e Adultos (AJA), do total de analfabetos brasileiros, apenas 2,5 milhões estão matriculados.

A pesquisa realizada pelo PNAD em 22 de maio de 2007 é a mais recente pesquisa divulgada pelo IBGE. Foram 147.851 residências que fizeram parte da pesquisa que revelou algo preocupante, como o de $42,7 \%$ dos estudantes que recorrem à EJA para dar continuidade aos estudos, abandonaram o ensino. A seguir são destacadas as quatro principais razões (veja a tabela 1), para o abandono dos cursos.

\begin{tabular}{|c|c|}
\hline \multicolumn{2}{|c|}{$\begin{array}{c}\text { QUATRO PRINCIPAIS RAZÕES PARA A } \\
\text { EVASÃO NA EJA }\end{array}$} \\
\hline $27,9 \%$ & $\begin{array}{l}\text { Horário das aulas é incompatível com o horário } \\
\text { de trabalho ou de busca pelo trabalho. }\end{array}$ \\
\hline $15,6 \%$ & Desinteresse pelo curso. \\
\hline $13,6 \%$ & $\begin{array}{l}\text { Horário das aulas é incompatível com atividades } \\
\text { domésticas. }\end{array}$ \\
\hline $13.6 \%$ & Dificuldade para acompanhar o curso \\
\hline $29,3 \%$ & Outras razões. \\
\hline
\end{tabular}

Segundo informação do MEC ${ }^{1}$ (Ministério da Educação e Cultura- 2006), "o abandono e a reprovação atingem $27 \%$ dos alunos". Esse índice é resultado de fatores como a incapacidade das escolas em fazer os alunos progredirem adequadamente ou ainda de estratégias para que o mesmo permaneça no sistema.

Ainda analisando dados da VI CONFINTEA, (2008, p. 04) sobre a situação educacional no Brasil, constata-se que no Centro-Oeste existem $8,3 \%$ do total dos 31 milhões de analfabetos funcionais. Observa-se que várias pessoas fazem suas matrículas 
visando estudar e, por algum motivo, muitos não concluem este objetivo. A desistência é notada logo nas primeiras semanas de aulas, visto que é percebida a diminuição dos alunos em sala de aula.

Por vários motivos tais como: cansaço ou estresse emocional no trabalho, indisposição, locomoção, falta de recursos financeiros para aquisição de materiais escolares, falta de segurança pública, motivação e tempo para realizarem as tarefas solicitadas pelos professores, problemas familiares, fadiga, impaciência e depressão, enfim, muitos outros motivos que não estão enumerados acima mais que também interferem diretamente ou indiretamente e colaboram para a evasão escolar.

Ao analisarmos os índices de evasão na Escola Municipal Rui Barbosa, percebe-se que segundo o gráfico 1 , a porcentagem de evadidos no $1^{\circ}$ período do $1^{\circ}$ segmento de EJA é expressiva.

\section{Gráfico 1}

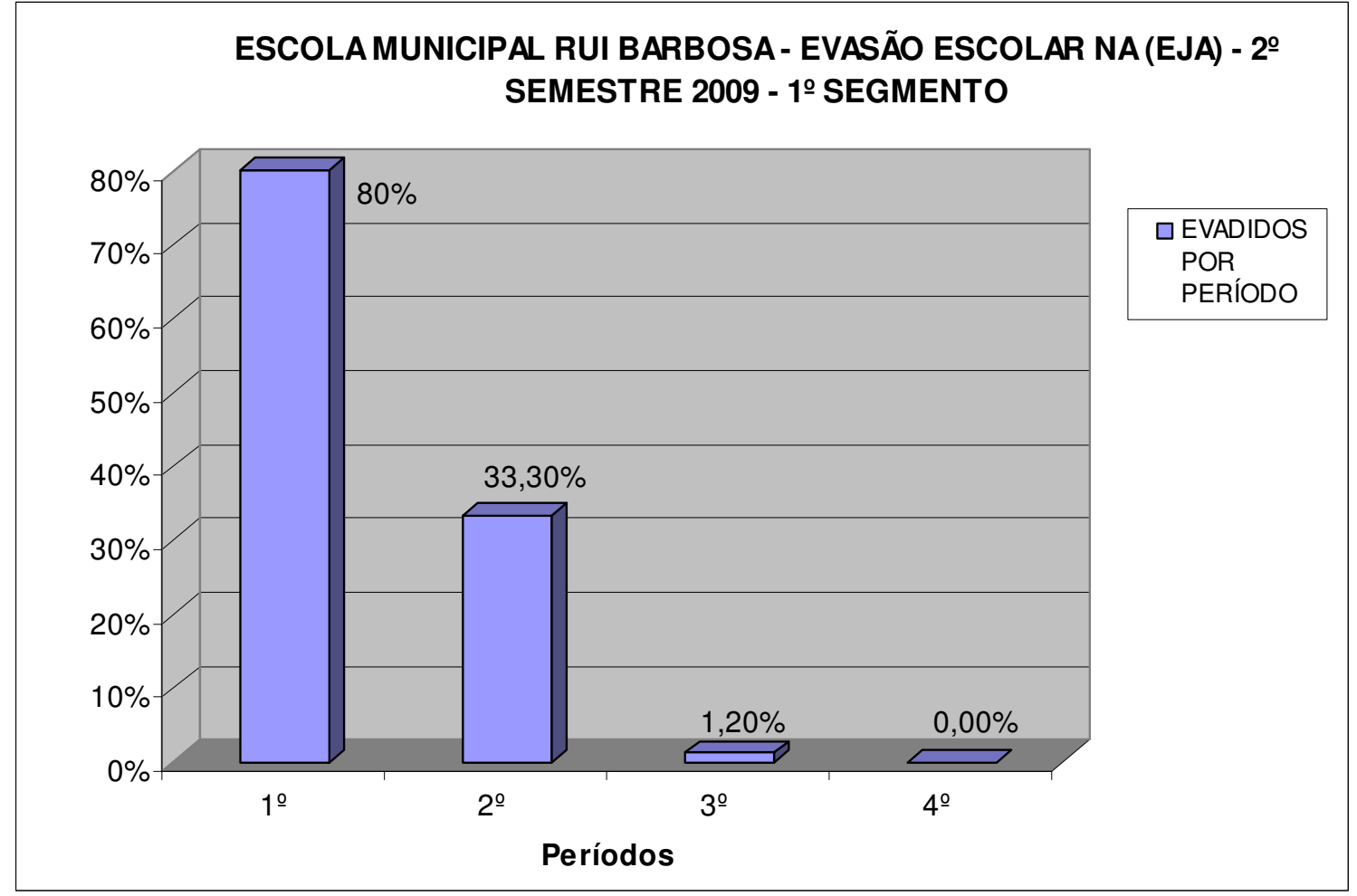

Fonte: Ata de Resultado Final EJA - 2을 Semestre de 2009

Vale enfatizar que na passagem do $4^{\circ}$ período do $1^{\circ}$ segmento, (onde não existia abandono), para o $1^{\circ}$ período do $2^{\circ}$ segmento, (veja o gráfico 2) a evasão passa a ser considerável, e a situação vai tomando proporções na passagem para $02^{\circ}$ período do mesmo segmento, onde mais da metade dos alunos abandonam os estudos, o que se repete no $3^{\circ}$ período. 


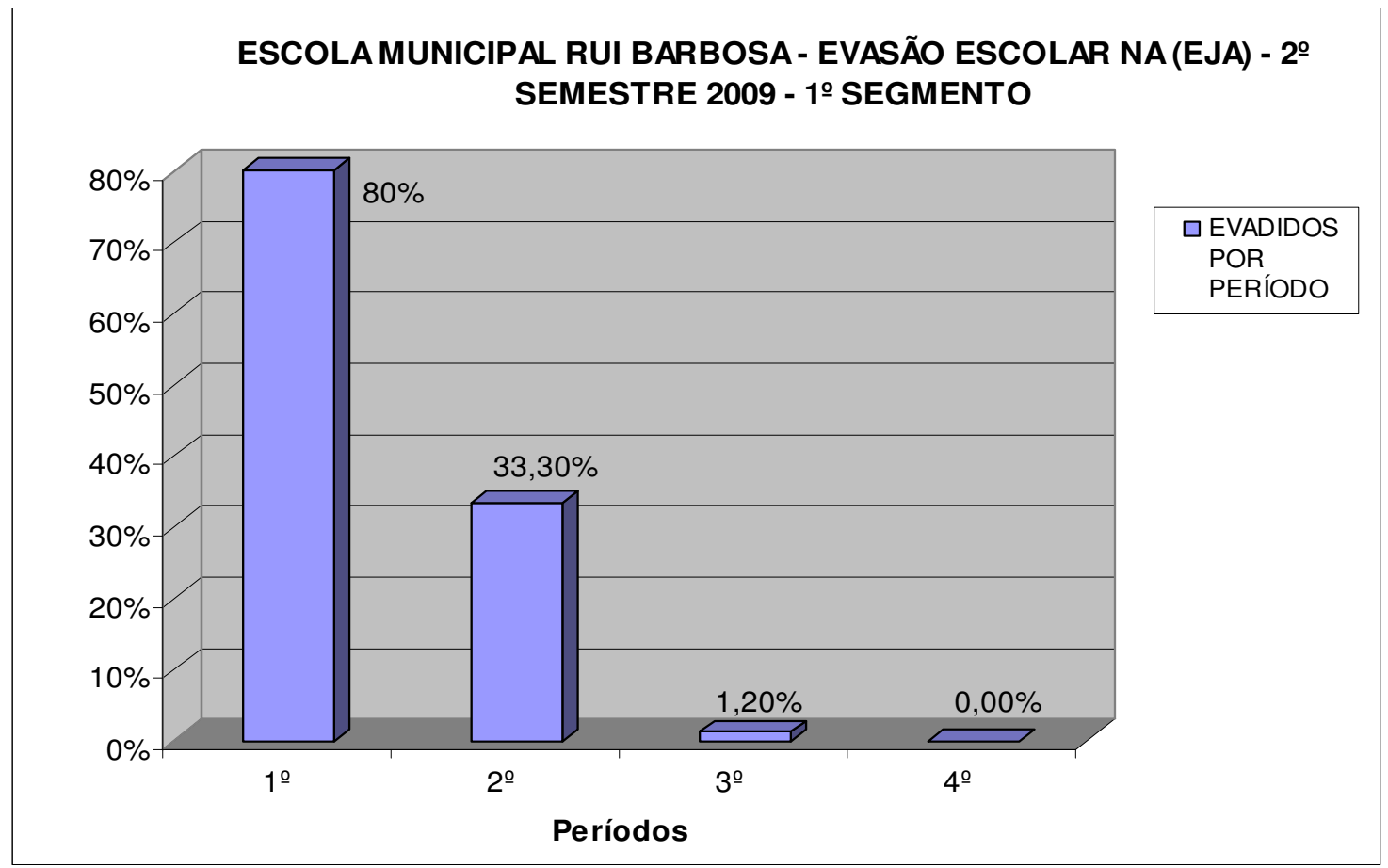

Fonte: Ata de Resultado Final EJA - $2^{\circ}$ Semestre de 2009)

\subsection{Obstáculos da EJA a Serem Vencidos}

Deve-se pensar conforme dados da VI CONFINTEA (2008), de que modo cada sujeito se apropria dos conhecimentos para si, para sua comunidade, e não somente para a necessidade de certificação, exigido em um sistema de reconhecimento formal da sociedade. Como documento burocrático, o certificado muitas vezes tem sido o "motor" que conduz jovens e adultos de volta à escola, sem que esta se dê conta de estar diante de uma bela oportunidade de transformar a expectativa inicial dos sujeitos, minimizando seu valor, e maximizando o valor do conhecer e da capacidade potencial de jovens e adultos no que se refere ao aprendizado.

Desafios são postos frente à exploração da mão-de-obra de jovens e adultos trabalhadores de camadas populares. Tais sujeitos estão submetidos ao mercado de trabalho, no que diz respeito à extensa carga horária, à baixa remuneração, a esforços físicos, enfim, condições que dificultam a permanência na escola.

A idéia é que em sala de aula não se deve somente ensinar, deve-se também aprender reciprocamente com eles, favorecendo a participação dos alunos no decurso das aulas, fazendo com que se sintam sujeitos atuantes na contextualização dos conteúdos ministrados, através do diálogo, para que possam conseguir participar de forma interativa durante sua formação. Assim: 
O educador já não é o que apenas educa, mas o que, enquanto educa, é educado, em diálogo com o educando que, ao ser educado, também educa. Ambos, assim, se tornam sujeitos do processo em que crescem juntos e em que os argumentos da autoridade já, não valem. Em que, para ser-se, funcionalmente, autoridade, se necessita de estar sendo com as liberdades e não contra elas. (FREIRE,1987, p. 38)

Desta forma, Paulo Freire destaca que os professores devem demonstrar a situação em que se encontram os alunos, para que a partir desta constatação, eles percebam que não podem permanecer na ingenuidade. Criar espaços para que eles possam construir uma consciência crítica quanto à realidade, isto é, despertando-os para o mundo. Aqui, reside o maior obstáculo a ser vencido.

\subsection{A necessidade de se elaborar um Projeto de Vida}

Pessoas que levam a vida sem propósitos são dirigidas pelos acontecimentos que ocorrem no cotidiano, nesse contexto, muitos são levados por eles, ficando dessa forma cada vez mais distante da concretização dos projetos idealizados. Todo e qualquer indivíduo tem sua vida dirigida por algo. Muitas pessoas são dirigidas por algum problema, por pressão, por prazo limitado, por alguma lembrança dolorosa, um temor pungente ou uma crença inconsciente. Várias pessoas são dirigidas pela culpa, tais pessoas passam a vida inteira fugindo do remorso. Sobre tal situação destaca Warren (2003, p. 26):

\footnotetext{
Pessoas dirigidas pela culpa são manipuladas por suas lembranças. Elas permitem que o passado controle o futuro, freqüentemente culpam a si mesmas por sabotarem o próprio sucesso. Somos produto de nosso passado, mas não temos de ser prisioneiro dele. Muitos são dirigidos pelo rancor e pela raiva, eles se apegam a mágoas, sem jamais superá-las. Em vez de aliviarem sua dor através do perdão, revivem-na de contínuo em sua mente. Algumas pessoas que são dirigidas pelo rancor "se fecham" e interiorizam sua raiva, enquanto outras "explodem" sobre os outros. Ambas as reações são perniciosas e não trazem nenhum benefício.
}

Muitos são dirigidos pelo medo. Seus temores são provavelmente o resultado de experiências traumáticas, de expectativas ilusórias, do crescimento em um lar extremamente severo. Independente do que tenha causado tal situação, pessoas dirigidas pelo medo com freqüência perdem grandes oportunidades por terem pavor de correrem riscos. Elas se comportam de maneira cautelosa, evitando se arriscar e tentando manter a situação vigente. Além do medo, a insegurança, a falta de equilíbrio emocional, dificulta o enfrentamento dos obstáculos. Nesse sentido destaca Freire (2009, p. 40):

Diante do medo, seja do que for, é preciso que, primeiro, nos certifiquemos, com objetividade, da existência das razões que nos provocam o medo. 
Segundo, se realmente existente, compará-los com as possibilidades de que dispomos para enfrentá-los com probabilidades de êxito. Terceiro, o que podemos fazer para, se for o caso, adiando o enfrentamento do obstáculo, nos tornemos mais capazes para fazê-lo amanhã. A questão que se apresenta é não permitir que o medo facilmente nos paralise ou nos persuada de desistir de enfrentar a situação desafiante sem luta e sem esforço.

É necessário combater os motivos que levam os alunos a se evadirem da escola, fazer com que os alunos compreendam a importância dos estudos. Nesta abordagem destaca Freire (2009, p. 33) "que estudar é desocultar, é ganhar a compreensão mais exata do objeto, é perceber suas relações com outros objetos. Implica que o estudioso, sujeito do estudo, se arrisque, se aventure, sem o que não cria nem recria". Mas para que isso ocorra é necessário perseverança, paciência e tempo.

Muitos alunos alegam que se evadem por não terem tempo para realizarem as tarefas solicitadas pelos professores e por falta de recursos financeiros para aquisição de materiais escolares. Nesse contexto enfatiza Freire (2009, p. 34):

A consulta a dicionários e enciclopédias e a leitura de capítulos, ou trechos de livros podem ajudar na análise mais crítica de um tema e que a utilização destes instrumentos não é uma perda de tempo e sim um tempo fundamental. Poder consultar todo esse material é um direito que têm alunos, que corresponde ao dever das escolas de fazer-lhes possível a consulta, equipando ou criando suas bibliotecas, com horários realistas de estudo.

Muitos são guiados pelo materialismo, quando o desejo de adquirir se torna o único objetivo de vida. O impulso de sempre querer mais se baseia no conceito errôneo de que quanto mais poder aquisitivo mais se tornarão felizes, importantes e protegidas. Mas esses pensamentos são falsos, porque posses somente trazem felicidade temporária, uma vez que as coisas não se modificam, tais pessoas acabam se entediando e então passam a desejar modelos mais novos, maiores e melhores, além do mais, riquezas podem ser perdidas em poucos instantes, em virtude de uma enorme quantidade de fatores incontroláveis. A verdadeira proteção só pode ser garantida naquilo que nunca poderão ser tirada dos alunos, pois os valores não são determinados pelas posses e a sabedoria não pode ser tirada de quem a possua.

Outros são levados pela necessidade de aprovação. Eles permitem que as expectativas dos pais, esposas, filhos, professores ou outras pessoas de influência controle sua vida. Existem também os que são dirigidos pela pressão social, sempre preocupados com o que os outros poderiam pensar.

Ser controlado pelas opiniões dos outros é uma forma segura de deixar de lado os verdadeiros propósitos. Existem outras influências que podem dirigir a vida, mas todas levam ao mesmo impasse de não aproveitamento, estresse desnecessário e uma vida com 
projetos não realizados. "Sem propósitos, a vida é um movimento sem sentido, uma atividade sem direção e acontecimentos sem motivos. Sem eles a vida é trivial, mesquinha e inútil" Warren (2003, p. 28)

Diante do exposto, é necessário enfatizar a finalidade deste projeto de intervenção local, que é fazer com que os alunos freqüentem as aulas, assim diminuindo a evasão escolar, através de métodos que possibilitarão aos educandos estabelecerem seus projetos de vida, conscientizando-os que para atingirem tais projetos, a educação formal é uma fase obrigatória nesse busca, destacando a importância de se estabelecer propósitos de vida que culminem em um projeto executado com êxito.

Conquistar os propósitos da vida garantirá a execução de grandes projetos e fará com que a vida tenha sentido. Sem propósitos estabelecidos a vida não tem relevância ou esperança. Na EJA esses propósitos, condensados em um Projeto de Vida, devem funcionar como motivação para a continuidade dos estudos, enfrentamento e rompimento dos vários tipos de obstáculos que aparecerão durante os semestres letivos. Dessa forma se os alunos tiverem um Projeto de Vida à evasão escolar será combatida.

\section{OBJETIVO GERAL}

Promover a permanência de alunos na Escola Municipal Rui Barbosa auxiliando-os a adotarem uma postura persistente na busca dos propósitos com vista à realização de seu Projeto de Vida, como forma de empoderamento ao combate a evasão escolar.

\subsection{Objetivos Específicos}

Construir propósitos de vida com vistas ao combate a evasão escolar;

Diminuir a evasão escolar através de oficinas de ensino, que enfatizem a busca pelo Projeto de Vida;

Destacar a importância da educação formal como uma das fases obrigatórias para a concretização do Projeto de Vida;

Construir noções de cidadania através de oficinas de ensino, dando ênfase a diversidade existente na EJA. 


\section{ATIVIDADES/RESPONSABILIDADES}

Este projeto será desenvolvido em três fases pelos professores de todas as disciplinas que lecionam na EJA, atuantes no $1^{\circ}$ e $2^{\circ}$ segmento, no período noturno da Escola Municipal Rui Barbosa, com o suporte da coordenação e direção da escola. $O$ Projeto foi idealizado com o intuito de reverter às estatísticas sobre a evasão escolar e passar aos educandos através de entretenimento, noções sobre o quadro crítico, representado pelos números de evadidos da modalidade EJA e, sobretudo despertar seu interesse, através de métodos de elaboração de propósitos específicos que serão abordados neste projeto que visem à formação física, emocional e intelectual através de atividades que promovam a formação do cidadão, sendo assim, pretende-se transformar a vida de seus alunos, dando e eles um novo sentido através da educação, chegando o mais próximo possível da concretização de seus projetos de vida.

Primeira fase - Constatação

A primeira fase será iniciada no mês de agosto em que ocorrerá a identificação do público alvo (alunos), adotando-se os seguintes critérios:

$1^{\circ}$ ) estatístico: os alunos que obtiverem $50 \%$ de falta no primeiro mês de aula, (constatado através do diário de classe), em todas as disciplinas serão os escolhidos para participarem das oficinas de ensino e serão visitados na segunda fase do projeto;

$\left.2^{\circ}\right)$ subjetivo: os educandos que se demonstrarem mais desmotivados no decorrer das aulas, também serão convidados a participar do projeto. Entende-se que esse subjtevismo será exercido tanto pelos professores, quanto pelos alunos, ou seja, os alunos que não forem constatados pelos professores e que desejarem participar do projeto, podem solicitar seu ingresso junto a coordenação do projeto.

Ainda neste primeiro mês será levantado pelos professores as causas da infrequência, através de relatórios que serão entregues aos coordenadores do projeto, sobre os alunos que foram constatados, seja pela infrequência ou desmotivação, no período de observação.

Segunda fase - visitação

$\mathrm{Na}$ segunda fase será iniciado o Combate a evasão escolar através de visitas domiciliares. Vale ressaltar que essa ação já foi realizada no início do ano letivo pela 
diretora juntamente com as professoras que atuam no primeiro segmento de EJA, e que os resultados foram positivos, pois grande foi o número de alunos que voltaram a ocupar os bancos escolares da Escola Municipal Rui Barbosa.

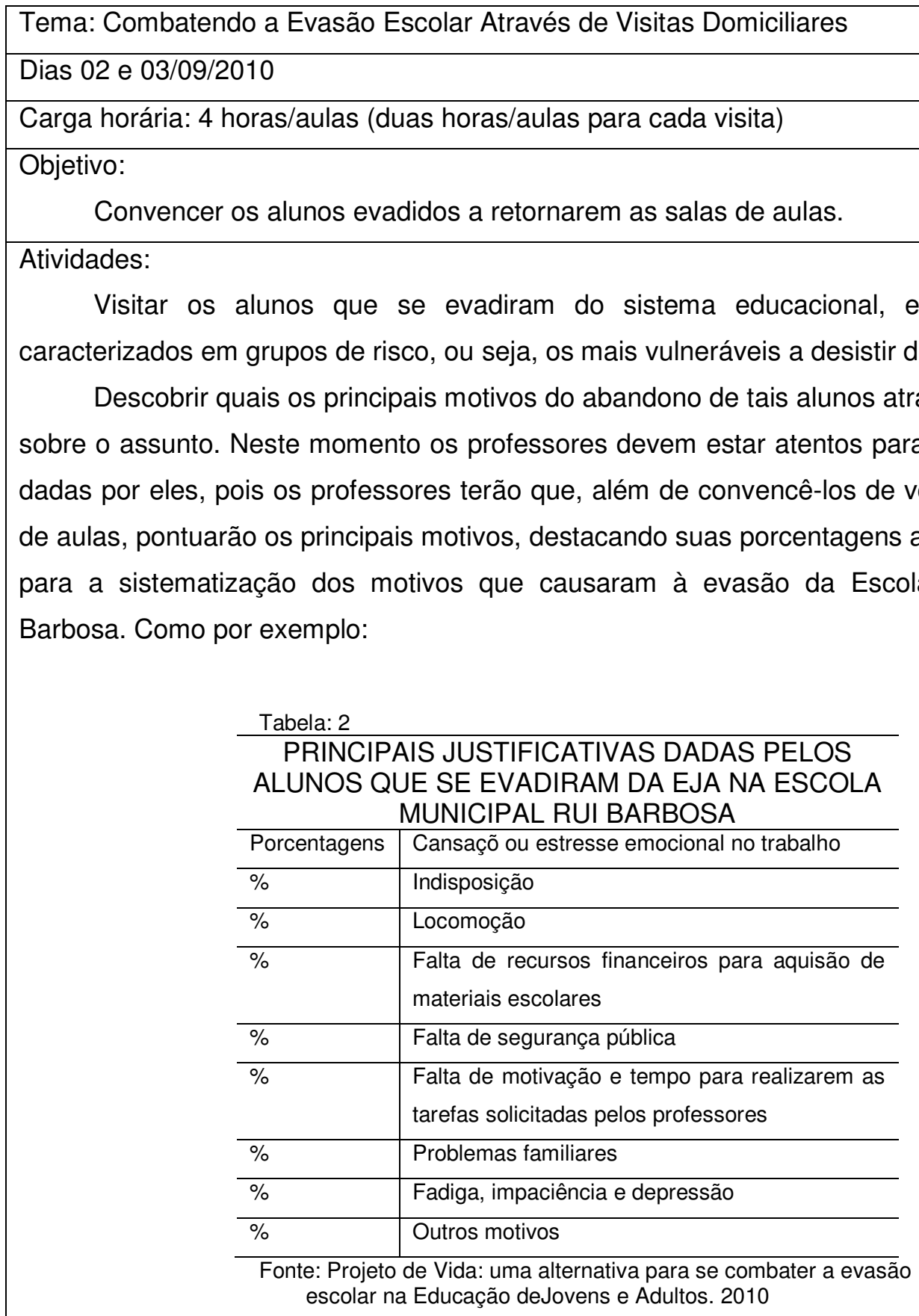

Em seguida os professores devem fazer com que os alunos compreendam o sentido da marginalização econômica, que aproveita a mão-de-obra dos trabalhadores com baixa escolaridade, incorporando a sua produção às riquezas nacionais, sem ao mesmo tempo 
valorizar o trabalho de quem os produz. Nesse contexto os professores devem se comprometer a realizar uma prática escolar diferenciada, mas não empobrecida, visto que, lecionar para as camadas populares um ensino de baixa qualidade contribui para o aumento de índices de evasão escolar e repetência.

Avaliação:

Serão avaliadas as atividades desta oficina nos dias posteriores, através da visualização dos alunos que tomaram a decisão de voltarem aos estudos.

Terceira Fase - execução

Nessa fase, o projeto ocorrerá com a montagem das oficinas de estudo, que se dará da seguinte forma: com antecedência de dois dias, os professores e coordenadores do projeto se reunirão para abordar o papel de cada ator nas oficinas, a sala de aula que será reservada e o material despendido para tal.

Os temas das oficinas serão:

1 Conseqüências da Evasão Escolar

2 Motivação Escolar e Combate a Evasão

3 Como Planejar Propósito para a Execução de Projetos

4 Conhecendo seus Projetos

5 Diversidade na Educação de Jovens e Adultos e Cidadania.

\section{Oficina 1 - Tema: Conseqüências da Evasão Escolar}

Dia 16/09/2010

Carga horária: 4 horas/aulas

Objetivo:

Sensibilizar os alunos sobre a questão da evasão escolar além de desenvolver a compreensão de que no competitivo mercado de trabalho é imprescindível a conclusão dos estudos.

Atividades:

Associar o futuro de um aluno que possua instrução formal e outro que não a possua. Utilizando o data show para que eles visualizem as ilustrações sobre as decisões tomadas no presente e suas conseqüências para o futuro.

A partir desse momento, os alunos (que já foram alfabetizados) devem escrever suas próprias reflexões em uma folha de papel A4, sobre cada uma das possibilidades propostas. Os alunos do $1^{\circ}$ segmento (que ainda não foram alfabetizados) farão suas reflexões oralmente ou por meio de desenhos, recortes e imagens. Será dado um tempo 
para a execução desta atividade e depois que todos fizerem suas reflexões será dado oportunidade para que haja o dialogo entre todos sobre a questão levantada e suas relações com o tema, neste momento os professores atuarão como mediadores do diálogo. Avaliação:

$\mathrm{Na}$ finalização da oficina serão entregues todas as folhas contendo reflexões aos professores regentes, que por sua vez estarão avaliando o nível de percepção dos alunos a cerca do tema proposto na oficina.

Cabe ressaltar que como forma de motivação os professores devem presentear os alunos com uma porcentagem que chegue a $20 \%$ de pontos em suas respectivas disciplinas.

Oficina 2 - Tema: Motivação Escolar e Combate a Evasão

Dia 30/09/2010

Carga horária: 4 horas/aulas

Objetivo:

Fazer com que os alunos freqüentem as aulas através da motivação escolar.

Atividades:

Com o auxílio de um aparelho de tocar CD, fazer com que os alunos oussam a música: tente outra vez de Raul Seixas;

Utilizando um aparelho de DVD para mostrar aos alunos algum dos vídeos motivacionais;

Após a visualização do filme, abrir um espaço para que haja a reflexão sobre a letra da canção e o filme. Nesta atividade os professores direcionarão o dialogo para o sentido da motivação que é o impulso que vem de dentro e que influencia diretamente na maneira de comportamento do indivíduo, e relacioná-la ao combate a evasão escolar.

Avaliação:

Nesta atividade será avaliada a capacidade de assimilação das reflexões e a forma de pô-las em prática, visando o objetivo da oficina de estudo.

Oficina 3 - Tema: Como Planejar Propósito para a Execução de Projetos

Dia 14/10/2010

Carga horária: 4 horas/aulas

Objetivo:

Direcionar os alunos sobre a escolha dos propósitos que visem alcançar os projetos idealizados. 
Atividades:

Serão distribuídas folhas de papel A4 para todos os alunos e em seguida, será solicitado que todos escrevam seus objetivos (aspirações), a profissão que gostariam de exercer no futuro, enfim articulando os primeiros passos de seus projetos de vida. Neste momento os professores devem enfatizar que os alunos ao realizar tais escolhas devem ser precisos, pois o mesmos terão que ser alcançados, mesmo que seja a longo prazo;

Explicar para os alunos que o planejamento é a trajetória que será traçada para se chegar à conclusão de tais objetivos (pretensões) e profissões. Pedir para que os alunos escrevam quais são as trajetórias que eles pretendem percorrer para se chegar ao que foi proposto anteriormente;

Em seguida explicar para os alunos que o projeto é a idéia ou a forma de se executar o que se foi idealizado no futuro e que o propósito é a determinação com que si deverá agir para se chegar à concretização do projeto. Os professores devem destacar que todos os alunos devem planejar bem suas vidas através de propósitos audaciosos. Em seguida pedir para que os alunos escrevam as formas de se executar o que eles idealizaram, ressaltando que não devem ser rígidos consigo, e que necessitam aproveitar todas as oportunidades que aparecerem, mesmo que não façam partes das metas estipuladas.

Avaliação:

$\mathrm{Na}$ finalização da oficina serão entregues todas as folhas contendo os projetos e as formas de planejamento para a execução do mesmo aos professores regentes, que por sua vez estarão analisando se existe coerência entre o planejamento, as metas e os propósitos para se chegar à execução de seus projetos de vida;

Caso haja algum erro ou divergência os professores esclarecerão as formas corretas das ações a serem tratadas com os respectivos alunos.

Oficina 4 - Tema: Conhecendo seus Projetos

Dia 21/10/2010

Carga horária: 4 horas/aulas

Objetivo:

Fazer com que os alunos conheçam a fundo seus projetos.

Atividades:

Iniciar a oficina perguntando se os alunos mudaram ou não de projetos, se eles se lembram quais eram seus projetos que foram estipulados na oficina que tinha por tema: como planejar propósitos para a execução de projetos. Em seguida devolver os papéis que foram recolhidos na penúltima oficina para os alunos, para que eles regatem os projetos e suas trajetórias. 
Explicar que quando se conhece mais profundamente seu projeto a vida fica simplificada, pois através dele, os alunos definirão o que deve ou não se fazer, pois quem não conhece seu projeto tenta realizar além do que deve. Neste momento será distribuído outra folha de papel A4 para os alunos, pedindo que sejam anotados o que eles não devem fazer, destacar também quais são os principais empecilhos que poderão ocorrer durante o processo de busca de seus projetos.

Explicar que durante a trajetória para a conclusão de seus projetos, aparecerão vários testes, porém os mesmos visam desenvolver o caráter das pessoas. Uma vez que os alunos tenham compreendido que a vida é um teste, eles perceberão que nada é insignificante na vida. Mesmo o menor incidente é relevante para o desenvolvimento do caráter. Cada dia é importante, e cada segundo é uma oportunidade de crescimento. Solicitar que os alunos escrevam quais serão os maiores e mais difíceis testes que serão enfrentados para a concretização dos projetos idealizados.

Explicar que a importância das coisas pode ser medida pelo tempo que se investi, ou seja, quanto maior o tempo dedicado a alguma tarefa, mais se demonstrará a importância e o valor que ela tem. Neste momento pedir para que os alunos escrevam em quanto tempo será gasto para se chegar à conclusão do projeto e quanto tempo eles pretendem dedicar por dia para que seja alcançado o projeto no tempo determinado.

Será determinado tempo e oportunidade para que haja o diálogo coletivo sobre as determinações dos problemas que ocorrerão e sobre o enfrentamentos das dificuldades para a conclusão dos projetos.

Avaliação:

$\mathrm{Na}$ finalização da oficina serão entregues todas as folhas contendo o que não deve ser feito durante a fase de ação do planejamento, os principais empecilhos, os maiores e mais difíceis testes, tempo determinado e o período dedicado por dia para a execução do projeto. Os professores regentes, que por sua vez estarão avaliando se os alunos estão realizando as atividades propostas na oficina.

Oficina 5 - Tema: Diversidade na Educação de Jovens e Adultos e Cidadania

Dia 28/10/2010

Carga horária: 4 horas/aulas

Objetivos:

Conscientizar os alunos sobre o respeito e a atenção que deve ser dada à diversidade étnico racial, cultural e regional, de gênero, econômica, religiosa, de condições mentais, de privação de liberdade, de aspectos físicos e psíquicos, dentro da EJA. Identificar os símbolos do Brasil e do Município de Valparaíso de Goiás, conhecendo 
seus históricos e significados, suas particularidades, com ênfase em resgatar o amor e 0 respeito no sentido de prepará-los para o exercício da cidadania.

Atividade:

Utilizando um computador com acesso a internet e um data show para que os alunos visualizem o vídeo "O Povo Brasileiro", baseado na obra do antropólogo Darcy Ribeiro (1913 - 1997), a partir das matrizes Tupi, Lusa e Afro. Momento este que também será visualizado os seguintes vídeos: Brasil Caboclo, Caipira, Crioulo, Sertanejo, Sulinos;

Serão devolvidas as folhas resgatadas na última oficina, que tinha por tema: conhecendo seus projetos, com as devidas observações e em seguida será distribuídas novas folhas em que os alunos deverão escrever as principais considerações sobre os vídeos;

Os professores explicarão que a EJA situa-se como um campo específico de direito de excluídos a uma chance de poderem se reintegrar de forma mais digna a sociedade. Destacando que isso se fará através da alfabetização e continuidade da escolarização, levando-se sempre em consideração à diversidade, respeitando as desigualdades sociais.

Será determinado tempo e oportunidade para que haja o diálogo (debate) coletivo sobre os vídeos. Momento este que deve favorecer a quebras de muitos preconceitos que estão incrustados em alguns alunos. Os professores serão os mediadores dos debates.

Logo após o debate, será distribuído folhas para os alunos contendo a letra dos hinos do Brasil e do município de Valparaíso de Goiás. Com o auxílio de um aparelho de tocar $C D$, fazer com que os alunos ousam e cantem juntos os hinos do Brasil e do Município de Valparaíso de Goiás. A partir desse momento apresentar as respectivas bandeiras e os respectivos símbolos (escudo, brasão) e explicar os seus significados.

Avaliação:

$\mathrm{Na}$ finalização da oficina serão entregues todas as folhas contendo as principais considerações sobre os vídeos. Os professores estarão avaliando a participação no debate as reflexões sobre os vídeos e se os alunos cantaram os respectivos hinos.

O relatório final do projeto será realizado depois do conselho de classe. Sendo reservado dois dias para o levantamento de dados sobre os alunos que se afastaram do sistema educacional, procurando destacar as causas de tal evasão. Serão previstos mais dois dias para a construção dos gráficos demonstrativos e a elaboração de conclusões sobre a evasão no período em que se realizou o projeto de intervenção local. 


\section{CRONOGRAMA}

\begin{tabular}{|l|l|}
\hline $\begin{array}{l}\text { Primeira fase Primeira fase Constatação do Público Alvo.__ } \\
\text { (dez horas/aulas, observação de infrequência e desmotivados, e dez } \\
\text { horas/aulas, relatórios sobre as causas da infrequência e desmotivação). }\end{array}$ & 20 horas/aulas \\
\hline $\begin{array}{l}\text { Segunda fase - visitação_ } \\
\text { (duas horas/aulas para cada oficina). }\end{array}$ & 4 horas/aulas \\
\hline $\begin{array}{l}\text { Terceira fase - execução__anoras/aulas } \\
\text { (duas horas/aulas para cada visita) }\end{array}$ & 16 horas/aulas \\
\hline $\begin{array}{l}\text { Relatório Final do Projeto _quatro horas/aulas para a contagem dos alunos que se evadiram e } \\
\text { quatro horas/aulas para o levantamento das causas do afastamento. } \\
\text { Quatro horas/aula para a construção dos gráficos e quatro horas/aula } \\
\text { para as comparações, alcance das metas e conclusões finais do projeto. }\end{array}$ & \\
\hline Carga horária Total _ & 72 horas/aulas \\
\hline
\end{tabular}

\section{PARCEIROS}

Corpo docente - O corpo de professores da entidade com qualificação diversificada em ciências humanas ou em ciências exatas, nos diferentes níveis de titulação, permitirá ao aluno contato como as múltiplas perspectivas relacionadas às atividades propostas pelo projeto e cada professor buscará uma ação integrada de sua linha de conhecimento. Planejando e pondo em práticas as ações juntamente com o suporte técnico da coordenação e direção da escola visando à execução dos objetivos com êxito.

\section{ORÇAMENTO}

Este Projeto será desenvolvido com o material didático disponível na Escola Municipal Rui Barbosa, portanto o que será gasto estará incluído nas verbas estaduais e municipais destinadas à instituição de ensino. O projeto Evasão Escolar e Projeto de Vida para ser executado com êxito conta com a colaboração, dedicação voluntária de todos os parceiros neste desafio que aqui é proposto. 


\section{ACOMPANHAMENTO E AVALIAÇÃO}

Os critérios de avaliação deste Projeto será o alcance satisfatório quanto à diminuição da evasão escolar em um curto espaço de tempo, que será demonstrado através de gráficos que indicarão a porcentagem (veja o gráfico 4 e 5). Os resultados devem evidenciar a eficácia, principalmente no que se referem ao empenho do corpo docente e discente da Escola Municipal Rui Barbosa.

\section{Gráfico 4}

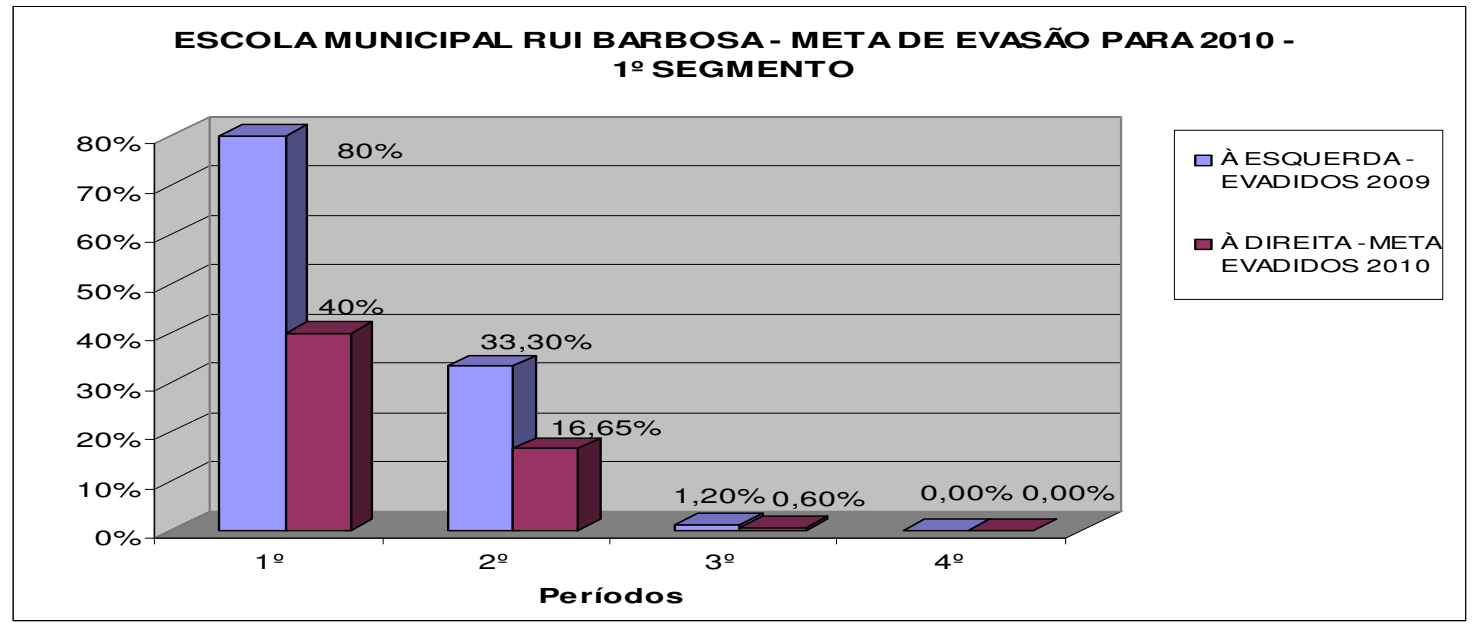

Fonte: Baseado na Ata de Resultado Final EJA - 2오 Semestre de 2009

Gráfico 5

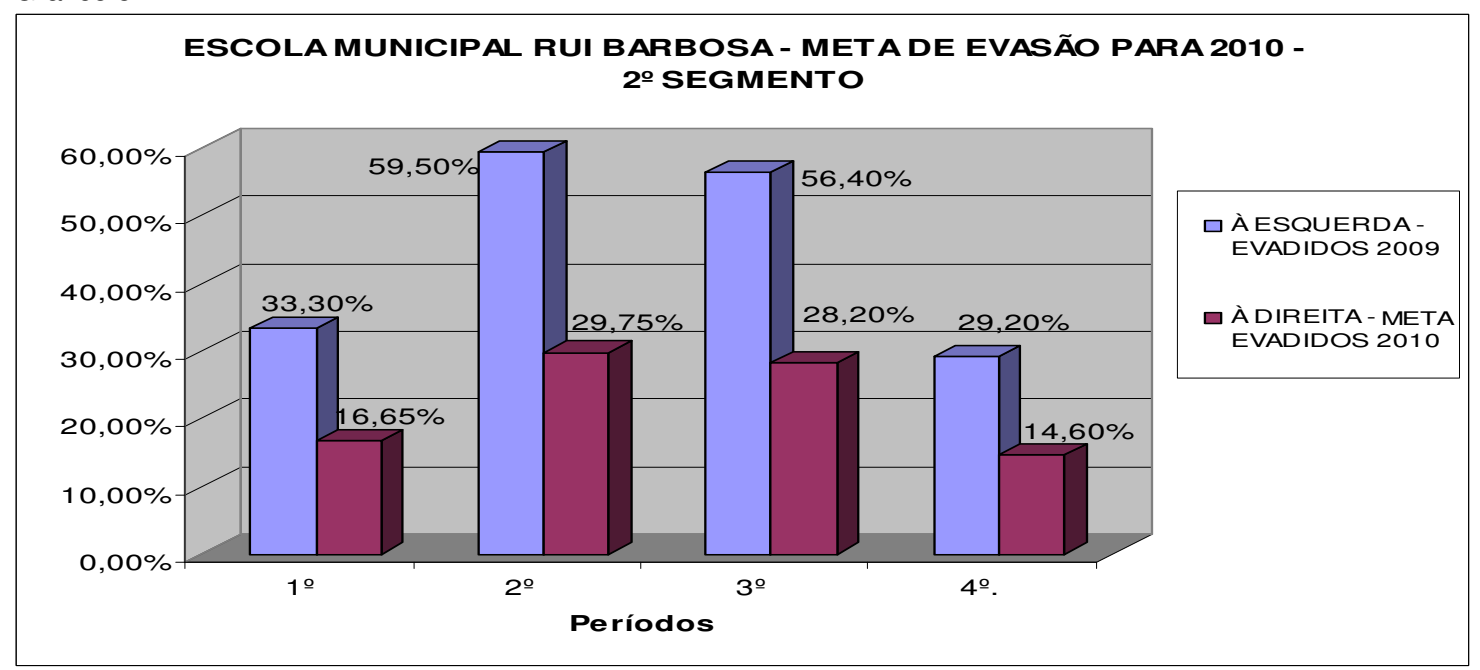

Fonte: Baseado na Ata de Resultado Final EJA - 2ำ Semestre de 2009 


\section{REFERÊNCIAS}

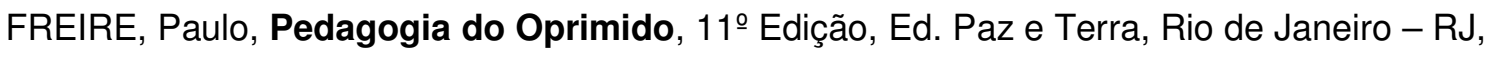
1987, p. 38.

FREIRE, Paulo, Professora Sim tia Não, cartas a quem ousa ensinar, $21^{\circ}$ Edição, Ed. Olho d'água, São Paulo - SP, 2009, págs. 33, 34 e 40.

WARREN, Rick, Uma Vida com Propósitos - Você não está aqui por acaso, Ed. Vida, São Paulo-SP, 2003, págs. 26, 28 e 38.

Sites Consultados:

DOCUMENTO BASE NACIONAL PREPARATÓRIO À VI CONFITEA. Disponível em:

$<$ www forumeja.org.br/files/docbrasil.pdf>, acessado em 25 de fevereiro de 2010, págs. 4,19 MINISTÉRIO DA EDUCAÇAÕ E CULTURA. Disponível em:

<www.nutep.adm.ufrgs.br/projetos>, acessado em 20 de abril de 2010.

${ }^{1}$ COMBATENDO A EVASÃO ESCOLAR. Disponível em:

<http://nutep.adm.ufrgs.br/projetos/RelatSantaMaria.html>, acessado em 02 de abril de 2010. 


\section{ANEXOS}

1 Aplicação do Projeto de Vida: uma alternativa para se combater a evasão escolar na Educação de Jovens e Adultos

\section{FICHA DE PARTICIPAÇÃO/PRESENÇA}

Data: 12010

Grau:

Período:

Turma:

Nome da Oficina:

Alunos

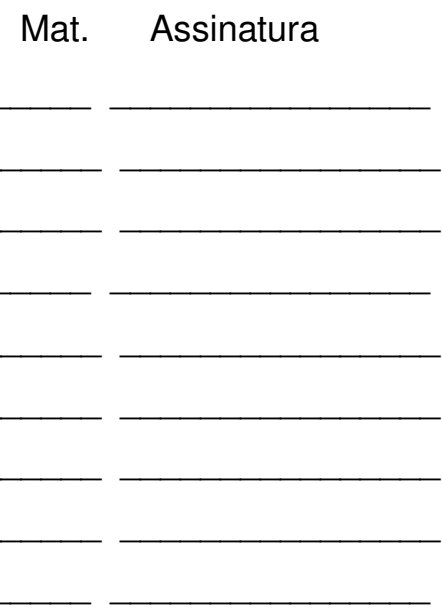

Presente

( )S ( ) N

( ) $\mathrm{S}(\mathrm{)}) \mathrm{N}$

( ) $\mathrm{S}($ ) $\mathrm{N}$

( )S ( ) N

( ) $\mathrm{S}(\mathrm{)}) \mathrm{N}$

( ) $\mathrm{S}(\mathrm{)}) \mathrm{N}$

( )S ( ) N

( ) $\mathrm{S}($ ) $\mathrm{N}$

( ) $\mathrm{S}($ ) $\mathrm{N}$

( )S ( ) N

( )S ( ) N

( ) $\mathrm{S}(\mathrm{)}) \mathrm{N}$

( ) $\mathrm{S}(\mathrm{)}) \mathrm{N}$

( ) $\mathrm{S}(\mathrm{)}) \mathrm{N}$

( )S ( ) N

Professores Orientadores: 
2 Relatório de Participação no Projeto de Vida: uma alternativa para se combater a evasão escolar na Educação de Jovens e Adultos

DADOS

A ser preenchido pelo(s) professore(s)

PARTICIPANTE DISCIPLINA MATR.

1.

2.

3.

4.

Nome da Oficina:

Tema:

Data: /2010.

Objetivos:

Atividades a serem desenvolvidas:

Aos dias do mês de os(as) professores(as) acima relacionados(as) estiveram presentes na Escola Municipal Rui Barbosa para participarem do Projeto de Vida: uma alternativa para se combater a evasão escolar na Educação de Jovens e Adultos - que visa oferecer a permanência dos alunos no sistema educacional, realizando um trabalho de relevante importância.

Os trabalhos foram realizados conforme o cronograma pré-estabelecido, tendo primeiramente a intervenção do(a) coordenador(a) para um(a) rápido(a) apresentação do grupo junto aos alunos e explicações gerais sobre o que ocorreria. A partir deste ponto, todo o resto ficou a cargo dos professores integrantes do grupo que conduziram as atividades diversas - acima relacionadas.

Este relatório deverá ser arquivado nos documentos referentes ao Projeto de Vida: uma alternativa para se combater a evasão escolar na Educação de Jovens e Adultos. 
3 Avaliação do Projeto de Vida: uma alternativa para se combater a evasão escolar na Educação de Jovens e Adultos

A ser preenchido(a) pelo coordenador(a) do projeto

1. Houve Pontualidade?

( ) Sim ( ) Não

2. Todos dos integrantes estavam presentes e tiveram participação significativa?

( ) Sim ( ) Não

3. O projeto foi entregue antecipadamente?

( ) $\operatorname{Sim}($ ) Não

4. Os integrantes demonstraram segurança e seriedade no trabalho?

( ) $\operatorname{Sim}($ ) Não

5. Houve registro fotográfico?

( ) Sim ( ) Não

Outras ocorrências/observações:

Sem mais para o momento, atesto e dou fé datando e assinando este.

Valparaíso de Goiás - GO, de de 2010.

Coordenador(a) do Projeto 